\title{
A eficácia da educação permanente na percepção da equipe de enfermagem de um hospital filantrópico do Paraná
}

\author{
The effectiveness of permanent education in the perception of the nursing team \\ of a philanthropic hospital of the state of Paraná
}

La eficacia de la educación permanente en la percepción del equipo de enfermería de un hospital filantrópico de paraná

Hellen Priscila Farias Moletta ${ }^{1}$, Márcio José de Almeida², Elaine Rossi Ribeiro ${ }^{3}$

\author{
${ }^{1}$ Mestre em Ensino nas ciências da saúde (FPP) e Professora do curso de Psicologia \\ da Faculdades Pequeno Príncipe- FPP - Curitiba - PR \\ ${ }^{2}$ Doutor em Saúde Pública. Pesquisador docente da Faculdade Pequeno Príncipe - FPP - Curitiba-PR \\ ${ }^{3}$ Doutora em Medicina - Clínica-cirúrgica. Pesquisadora docente da \\ Faculdade Pequeno Príncipe - FPP - Curitiba-PR
}

\section{RESUMO}

\begin{abstract}
A Educação Permanente é a aprendizagem constante dos indivíduos envolvidos em uma prática profissional. Objetivou-se nesta pesquisa analisar a compreensão da equipe de enfermagem em relação à eficácia da educação permanente; descrever a experiência da equipe de enfermagem sobre a educação permanente; identificar os benefícios e dificuldades apontados pela equipe de enfermagem sobre a educação permanente. Trata-se de uma pesquisa exploratório-descritiva com abordagem qualitativa, a coleta de dados foi realizada através de entrevistas com a equipe de enfermagem. O estudo ocorreu em março de 2016 em um hospital pediátrico de Curitiba, e as perguntas feitas na entrevista se referiam a saber qual é a compreensão dos profissionais da enfermagem referente a Educação Permanente. Os dados foram analisados por meio de categorização. Conclui-se que os profissionais da enfermagem compreendem a eficácia da educação permanente, reconhecem seus benefícios e identificam as dificuldades em participar das ações ofertadas pelo programa de educação permanente.
\end{abstract}

Palavras-chave: Educação Permanente. Enfermagem. Aprendizagem.

Autor de Correspondência:

*Hellen Priscila Farias Moletta. E-mail: hellenpris@hotmail.com 


\begin{abstract}
Permanent Education is the constant learning of individuals involved in a professional practice. The objective of this research was to analyze the nursing team's understanding of the efficacy of continuing education; to describe the experience of the nursing team on lifelong education; to identify the benefits and difficulties pointed out by the nursing team about lifelong education. This is an exploratory-descriptive research with a qualitative approach, data collection was performed through interviews with the nursing team. The study took place in March 2016 in a pediatric hospital in the city of Curitiba, and the questions asked in the interview referred to the nursing professionals' understanding of Permanent Education. Data were analyzed by means of categorization. It is concluded that nursing professionals understand the effectiveness of continuing education, recognize its benefits, and identify the difficulties in participating in the actions offered by the permanent education
\end{abstract}

Keywords: Permanent Education. Nursing. Learning.

\title{
RESUMEN
}

La educación permanente es el aprendizaje constante de los individuos involucrados en una práctica profesional. Se buscó en esta investigación analizar la comprensión del equipo de enfermería en relación a la eficacia de la educación permanente; describir la experiencia del equipo de enfermería sobre la educación permanente; identificar los beneficios y dificultades señalados por el equipo de enfermería sobre la educación permanente. Se trata de una investigación exploratoria-descriptiva con abordaje cualitativo, la recolección de datos fue realizada a través de entrevistas con el equipo de enfermería. El estudio ocurrió en marzo de 2016 en un hospital pediátrico de Curitiba, y las preguntas formuladas en la entrevista se referían a saber cuál es la comprensión de los profesionales de la enfermería referente a la Educación Permanente. Los datos se analizaron a través de la categorización. Se concluye que los profesionales de la enfermería comprenden la eficacia de la educación permanente, reconocen sus beneficios e identifican las dificultades en participar de las acciones ofrecidas por el programa de educación permanente.

Palabras clave: Educación permanente. Enfermería. El aprendizaje.

\section{INTRODUÇÃO}

A expressão Educação Permanente (EP) apareceu pela primeira vez na França em 1955. O termo foi oficializado em um documento pelo ministro da educação no ano de 1956. Esse documento foi determinante para a reforma do ensino público da época, pois o mesmo visava assegurar a continuação da educação após o período escolar ${ }^{1}$.

Em meados dos anos 1960 surgiram as primeiras pesquisas na Europa e nos Estados Unidos da América referente ao tema educação permanente. Nesta visão a UNESCO defendia que o processo de educação permanente é responsável por criar um diferencial no aprimoramento do capital humano, além disso, o impacto desse processo beneficiaria diretamente o desenvolvimento econômico de um país ${ }^{2}$.

Nos anos de 1980 e 1990 a OPAS (Organização Pan 
Americana de Saúde) desenvolve a proposta da Educação Permanente em Saúde (EPS) disseminando o seu conceito para o desenvolvimento de recursos humanos ${ }^{3}$.

No que se refere às políticas de saúde no Brasil, no ano de 1937, o governo federal instituiu Conferências Nacionais de Saúde a fim de articular e conhecer as ações tomadas pelos Estados na área da educação e saúde. Somente em 1941 a Primeira Conferência Nacional de Saúde ocorreu sob a responsabilidade do Ministério da Saúde e Educação.

Em 1980, o tema da VII Conferência de Saúde era a extensão dos serviços básicos de saúde. Isso era reflexo de um movimento que ocorria na sociedade que ansiava por uma reforma mais profunda no atendimento de saúde. Já em 1990, graças à democratização, a saúde ganhou rumos diferentes mediante a criação do SUS (Sistema Único de Saúde) atribuindo ao sistema à responsabilidade de ordenar a formação na área de saúde no Brasil.

As Conferências de Saúde, após o advento do SUS em 1990, passaram a ser dirigidas pelo CNS (Conselho Nacional de Saúde). Na XII Conferência, em 2003, o tema EPS foi abordado com ênfase. No relatório final desta conferência, ficou explícito que a EPS não pode ser considerada apenas como uma metodologia aplicável, mas sim como um modelo de política a ser seguido ${ }^{4}$.

No dia 13 de fevereiro de 2004, a Política Nacional de Educação Permanente em Saúde é instaurada pelo Ministério da Saúde (MS), por meio da portaria nº. 1996/GM. A Educação permanente em saúde nas instituições passa a ser considerada como uma forma de aprendizagem em que os profissionais integram o aprender e o ensinar ao desempenhar suas atividades do dia a dia e assim desenvolver suas competências 5 .

O processo de educação dos trabalhadores da saúde acontece no enfrentamento de problemas e situações práticas do cotidiano, o que leva ao desenvolvimento do sujeito. A transformação das práticas profissionais e da própria organização do trabalho podem ser resultados dos processos de educação permanente em saúde.

Considerando que a eficácia está relacionada com o alcance dos objetivos, sem necessariamente ter o foco no processo para este resultado com êxito ${ }^{6}$. A pergunta norteadora desta pesquisa é: Qual a compreensão da equipe de enfermagem em relação à eficácia da educação permanente?

Este estudo tem como objetivo analisar a compreensão da equipe de enfermagem em relação à eficácia da educação permanente.

\section{MÉTODO}

Caracteriza-se por ser uma pesquisa exploratória descritiva com abordagem qualitativa. O contexto da pesquisa foi em um Hospital Pediátrico na cidade de Curitiba - PR que possui 1951 funcionários, sendo 769 destes pertencentes à área da Enfermagem. Existe um setor específico na instituição que é responsável pelo Programa de Educação Permanente, o qual propõe ações educativas como: palestras, rodas de conversas, aulas práticas, treinamentos e simulações realísticas. Os objetivos destas práticas educativas são de reciclar informações e capacitar os participantes para a implantação de novos procedimentos. O público são todos os técnicos de enfermagem e enfermeiros, e estas ações oferecidas englobam o desenvolvimento de competências técnicas, comportamentais e gerenciais.

Os participantes escolhidos foram dois grupos diferentes de sujeitos, o grupo "1" profissionais com nível técnico em enfermagem e o grupo "2" enfermeiros. Os critérios de inclusão foram: (1) sujeitos que possuíssem vínculo empregatício com a instituição, (2) sujeitos que atuassem nos setores de assistência do hospital e com formação técnico em enfermagem, (3) sujeitos que tivessem participado do programa de educação permanente do hospital 
(4) sujeitos que possuíssem no mínimo um ano de admissão na instituição (5) sujeitos que aceitassem participar da pesquisa.

Para manter a privacidade dos participantes, seus nomes foram substituídos pelas seguintes abreviaturas: TEC para os profissionais Técnicos em Enfermagem e ENF para os profissionais Enfermeiros.

Para a coleta das informações foi utilizado um instrumento para nortear a entrevista com perguntas semiestruturadas. A análise das informações iniciouse com a transcrição na íntegra das entrevistas gravadas. Na sequência foi realizada uma leitura compreensiva do conteúdo de forma detalhada e minuciosa de todo o material com o objetivo de atingir os níveis mais profundos e salientar as ideias principais.

Em seguida à leitura, houve a organização do material por unidades de respostas conforme a frequência das mesmas com a finalidade de destacar as particularidades do conteúdo a ser analisado.

Para tal organização, foi elaborado um esquema com mapa conceitual através do software Mindjet MindManager 2016, para agrupar cada uma das respostas dos profissionais de cada área e assim facilitar a visualização e o entendimento das informações ${ }^{7}$.

Este estudo respeitou os princípios éticos estabelecidos pela Resolução 466/2012 que trata de pesquisa com seres humanos do Conselho Nacional de Saúde(8). Foi submetido ao comitê de Ética em Pesquisa das Faculdades Pequeno Príncipe para aprovação (sob número 1.370.227) da realização da pesquisa, conforme orientações das normas que regulamentam pesquisas com seres humanos ${ }^{8}$.

\section{RESULTADOS E DISCUSSÃO}

A coleta das informações aconteceu no mês de março de 2016 através de uma entrevista seguindo um roteiro de perguntas semiestruturadas, o número total de participantes entrevistados foi de 30 sujeitos, sendo 20 técnicos de enfermagem e 10 enfermeiros.

As características dos participantes de nível técnico em relação ao gênero foram de $90 \%$ sexo feminino e $10 \%$ sexo masculino. Já em relação ao estado civil, $50 \%$ eram casados, $45 \%$ eram solteiros e $5 \%$ eram divorciados.

Sobre os entrevistados do nível superior, nesse caso os enfermeiros, as características em relação ao gênero foi que $100 \%$ eram do sexo feminino. Em relação ao estado civil $70 \%$ eram casadas e $30 \%$ solteiras.

Após leitura extensiva das falas dos participantes, foi possível notar certa singularidade nas respostas dos profissionais técnicos com as respostas dos enfermeiros. Em busca deste refinamento foi evidente a convergência de pensamentos em alguns aspectos de determinadas perguntas, possibilitando realizar a triangulação dos dados com a "combinação e cruzamento de múltiplos pontos de vista". As categorias que emergiram foram:

\section{1- Aprendizagem}

Quando os profissionais de nível técnico foram questionados sobre "O que você entende por educação permanente em saúde? ”, a maioria relatou que a EPS estava ligada diretamente à aprendizagem do indivíduo por meio de treinamentos constantes, palestras e cursos afins, onde estes proporcionam aquisição de novos conhecimentos na área de trabalho. Os enfermeiros responderam com uma perspectiva bem parecida com a dos profissionais de nível técnico, porém um cunho conceitual prevaleceu, onde entendem que a EPS é um programa que tem como finalidade aprimorar profissionalmente tanto os técnicos de enfermagem quanto os próprios enfermeiros através da atualização frequente, visando o aprendizado diário em meio à rotina de trabalho. Com isso ambos os grupos relataram de forma contundente a raiz vertente da EPS, que é o 
aperfeiçoamento constante através de novos conhecimentos, e relataram de maneira recorrente a palavra aprendizagem. É extremamente necessário categorizar essa palavra a fim de discorrer sobre assunto tão significativo da EPS.

Os sujeitos, ao serem entrevistados a respeito do que entendem por educação permanente em saúde no hospital de Curitiba-PR, em sua maioria, compreendem que a EPS proporciona uma aprendizagem ao profissional, conforme as respostas a seguir dos técnicos de enfermagem e enfermeiros:

Educação permanente é sempre estar aprendendo mais, reciclando, atualizando o que já sabe. (TEC 3)

Seria tudo o que aprendemos no decorrer do dia a dia, e os treinamentos que fazemos conforme as novas rotinas e as novas coisas que aparecem, assim vamos recebendo as informações e vamos inovando. (TEC 15)

Educação permanente em saúde é um programa que foi criado para que estejamos sempre em crescimento, em evolução, principalmente na área da saúde que sempre tem algo mudando, sempre altera algo, para que haja essa interação esse aprendizado dos funcionários. (ENF 3)

Estar sempre aprendendo, sempre renovando, tem vários métodos, coisas novas, devemos estar sempre aprendendo. (ENF10)

Segundo as falas acima, os dois grupos consideram que a educação permanente está relacionada à oportunidade de aprender e atualizar os conhecimentos já obtidos sobre os diversos assuntos associados à saúde e ao mesmo tempo ensinar o que se aprende. Conforme Freire "quem ensina aprende ao ensinar, e quem aprende ensina ao aprender". Ou seja, quando o trabalhador ensina, concomitantemente ele aprende, pois é um processo em que ele reúne todo o seu conteúdo interno e externiza de forma singular e o outro que está recebendo a informação também ensina com suas expressões, perguntas e observações que podem trazer reflexões ao que se aprende e significar a aprendizagem.
No que diz respeito à dimensão pedagógica, observase que a EPS determina que as atividades educativas sejam desenvolvidas com base nos conceitos teóricometodológicos da educação permanente em saúde. Dessa forma, tem como objetivo transformar as práticas nos serviços de saúde, por meio de um processo de aprendizagem significativa, a partir da análise coletiva dos processos de trabalho com a participação das equipes multidisciplinares.

Conforme Ausubel ${ }^{11}$, "o conhecimento é significativo por definição. É o produto significativo de um processo psicológico cognitivo ("saber") que envolve a interação entre ideias "logicamente" (culturalmente) significativas, ideias anteriores ("ancoradas") relevantes da estrutura cognitiva particular do aprendiz (ou estrutura dos conhecimentos deste) e o "mecanismo" mental do mesmo para aprender de forma significativa ou para adquirir e reter conhecimentos."

Uns dos pilares do processo da aprendizagem significativa é o fato que ela se desenvolve em um ambiente de interação, neste caso a interação só existe mediante o envolvimento de duas ou mais pessoas, em um movimento de ações e reações, as mesmas podem ser das mais variáveis possíveis. Como comentado nas entrevistas, a troca de informações entre os profissionais de saúde oportuniza o enriquecimento do saber de cada indivíduo. Além disso, vale ressaltar que o conhecimento adquirido mediante as interações desenvolvidas entre os mesmos vem das próprias experiências "ancoradas" no cognitivo de cada profissional.

\section{2- Inovação do Conhecimento}

$\mathrm{Na}$ sequência dos questionamentos, a segunda pergunta realizada aos profissionais do nível Técnico em Enfermagem e Enfermeiro foi: "Como você percebe o processo de EPS no seu ambiente de trabalho?”

Ambos os grupos confirmaram de maneira expressiva que conseguem perceber que o programa EPS é ativo na instituição e que esse processo visa profissionais 
cada vez mais capacitados através da inovação do conhecimento, como bem comentaram em suas respostas. Portanto, como a inovação do conhecimento foi algo bem relativo a ambos os grupos, surge esta categoria a fim de explorar mais esse conceito que está ligado diretamente às diretrizes da EPS.

Os profissionais entrevistados revelaram que a EPS proporciona a evolução do profissional, à medida que ele realiza um upgrade dos conhecimentos técnicos mediante as ações educativas inovadoras.

Acho maravilhoso e gratificante o programa EPS, porque você sempre está aprendendo coisas novas e o que você já aprendeu você atualiza. (TEC2)

Acho que é muito importante para nós, desempenhamos nossas atividades com mais segurança, porque sempre estamos treinando e aprendendo, atendemos melhor os pais. (ENF10)

Os depoimentos acima apontam uma relação sobre o quesito inovação e o conhecimento profissional, onde os entrevistados reconhecem que a prática da educação permanente permite o aprimoramento dos processos internos relacionados ao ambiente de trabalho. Para o Ministério da Saúde, a Educação Permanente em Saúde "é aprendizagem no trabalho, onde o aprender e o ensinar se incorporam ao quotidiano das organizações e ao trabalho. Propõese que os processos de capacitação dos trabalhadores da saúde tomem como referência as necessidades de saúde das pessoas e das populações, da gestão setorial e do controle social em saúde, tenham como objetivos a transformação das práticas profissionais e da própria organização do trabalho, e sejam estruturados a partir da problematização do processo de trabalho"12.

\section{3- Falta de Tempo}

Quando realizada a pergunta "Você enfrenta algum problema para participar do Programa de EPS?", os profissionais do nível técnico em enfermagem foram unânimes em responder que consideram como um obstáculo a demanda alta de trabalho, e se expressaram com a frase "o setor é corrido". Os enfermeiros apresentaram respostas aproximadas dos técnicos relatando também a demanda alta de trabalho.

Um aspecto abordado pelos entrevistados do período noturno refere-se ao horário das ações educativas que ocorrem geralmente no início do plantão, momento onde acontecem atividades intensas no setor como: troca de equipe, preparação para o turno, ministração de medicamentos e procedimentos realizados pelos profissionais aos pacientes.

A dificuldade é que sempre acontece em horário de trabalho, às vezes vamos para o treinamento, nós deixamos de cuidar do paciente para irmos ao treinamento. Nesse ponto eles têm que ver essa necessidade, se é mais importante ir ao treinamento ou cuidar do paciente, quando retornamos ao setor, está tudo atrasado. (TEC7)

Acho o horário, quando é um início de plantão, tem muita coisa para fazer. (ENF7)

A questão de disponibilidade de tempo por parte da equipe é um fator prejudicial na implantação da EPS. O acúmulo de trabalho demonstrou ser um ponto impactante. A grande dificuldade encontrada é planejar as atividades relacionadas ao desenvolvimento técnico dos técnicos em enfermagem dentro da jornada de trabalho. Isso resulta em profissionais cada vez mais desmotivados no tocante ao programa de educação permanente, simplesmente por esta falta de tempo ${ }^{13}$.

\section{4- Déficit de profissionais}

Outra dificuldade que estes profissionais enfrentam para deixar seus postos a fim de participar das ações educacionais promovidas pela EPS é o déficit de colaboradores. Isso geralmente prejudica a realização de um remanejamento dos pacientes entre os colaboradores, mesmo que haja um planejamento adequado entre a equipe. 
É muito paciente, sobrecarrega, aí temos que deixar para ir, ai é bem complicado. (TEC10)

Eu acho que tem muita demanda e a gente não consegue se ausentar, e também falta de funcionários. (ENF8)

Quando se tem um déficit de funcionários a chance de um profissional participar do programa se torna escassa, o que compromete o desenvolvimento do programa. O problema não é só a falta de tempo para participar das ações propostas pela EP, mas sim outros problemas que isso acarreta aos profissionais. Quando existe essa lacuna de falta de funcionários, com certeza o ambiente de trabalho se torna difícil. A tendência é que o estresse aparecerá e junto com a insatisfação. Além disso, o profissional ativo fica desmotivado por causa da sobrecarga de trabalho, a sua qualidade no atendimento tende a cair e a sua saúde também pode ser impactada, pois o desgaste físico e mental é grande. Portanto, fica nítido que o déficit de funcionários no setor é um fator impactante que interfere na progressão do programa de EPS na instituição ${ }^{14}$.

Déficit de colaboradores no setor, então você não consegue sair, porque você tem uma carteira de paciente para cuidar, e você não consegue se desvincular. (TEC13)

Temos uma apresentação de atestados e muita falta de colaboradores no dia a dia, então isso dificulta que os colaboradores participem, pois sobrecarrega a equipe, é bem corrido mesmo. (ENF5)

\section{5- Segurança}

Existem duas perguntas que foram realizadas aos profissionais de nível técnico e eles apresentaram uma relação muito próxima, sendo a primeira pergunta: "Do seu ponto de vista quais benefícios que o Programa de EPS pode trazer para você?”, e a segunda: "Do seu ponto de vista quais benefícios que o Programa de EPS pode trazer para o paciente?". Apesar de serem dois questionamentos distintos em relação ao sujeito final, houve uma combinação nas respostas no tocante aos resultados colhidos através das respostas dos dois grupos pesquisados. Em sua maioria, as palavras expressadas foram sobre aprendizado e segurança.

Com os enfermeiros duas perguntas apresentaram uma relação muito próxima, sendo que a primeira pergunta foi: "Do seu ponto de vista quais benefícios que o Programa de EPS pode trazer para os técnicos em enfermagem e para você como enfermeiros? ", e a segunda foi: "Do seu ponto de vista quais benefícios que o Programa de EPS pode trazer para o paciente?”.

Um ponto relatado pelos entrevistados referente aos benefícios que a aplicação do programa de educação permanente traz, foi a questão da segurança dos profissionais da saúde. Tanto para os entrevistados de nível técnico em enfermagem quanto para os enfermeiros, ambos concordaram que todo o profissional que é bem qualificado nos quesitos teoria e prática, tem segurança e tranquilidade na realização de procedimentos gerando qualidade na prestação de serviço e a probabilidade de erros se tornarem mínimas. Para a Organização Mundial da Saúde, segurança do paciente consiste na ausência de dano potencial ou desnecessário para o paciente associado aos cuidados em saúde ${ }^{15}$.

Toda a assistência prestada por seres humanos corre o risco de ser ineficaz em algum momento. Contudo existem vários fatores que podem contribuir para que estes eventos adversos aconteçam, dentre tantos podemos destacar processos complexos implantados nas organizações ou até mesmo os seus problemas de planejamento. Eventuais falhas que atingem diretamente os pacientes devem ser diagnosticadas sempre. Entender que os processos podem falhar ou que estão falhando no momento da execução é o primeiro passo para que uma instituição possa adotar medidas corretivas. Portanto, as instituições devem estar sempre atentas para a melhoria de seus processos de forma contínua, pois o aprimoramento deles proporciona ao profissional a sensação de segurança em seu exercício profissional. As ações 
aprimoradas, na maioria das vezes corrigidas, devem gerar resultados positivos e confiáveis que façam a diferença na vida do paciente, diminuindo a incidência de erros e promovendo um ambiente seguro para o paciente e para o profissional ${ }^{16}$.

Evidenciou-se em algumas respostas que existe um temor muito grande quando se fala em segurança, pois pequenos erros podem ser fatais no ambiente de saúde. Por isso a importância de treinamentos regulares ajuda os profissionais a desenvolverem o seu trabalho com mais confiança. O resultado atrelado à qualidade do serviço e os índices de erros cada vez menores revelam ser um fator diferencial do programa EPS.

Acho que é a segurança, um bom trabalho, acho que o trabalho se deslancha mais rapidamente, o paciente vai ser bem assistido, acho que nesse sentido é bem importante. (TEC2)

Segurança porque a partir do momento que você tem uma equipe bem treinada o paciente será bem assistido, você como enfermeiro tem uma equipe que pode confiar, existe mais segurança para o profissional, para o enfermeiro e para o paciente. (ENF4)

\section{6- Qualidade no atendimento}

A qualidade na prestação de serviço deve ser constantemente buscada pelos profissionais de enfermagem com o propósito de oferecer aos pacientes um atendimento capaz de suprir as suas necessidades físicas e psicológicas. As características do profissional que preza pela qualidade em seu trabalho devem estar relacionadas ao seu desenvolvimento pessoal, que envolve o conhecimento de causa e a habilidade nos processos de enfermagem ${ }^{17}$.

Entende-se por qualidade o aperfeiçoamento contínuo exercitado a longo tempo visando sempre o cliente, ou no caso da enfermagem o paciente. O processo de melhorias constantes reflete na prática diária do indivíduo onde os resultados são evidenciados pelas partes interessadas, neste caso as partes que usufruem do atendimento prestado ${ }^{18}$.

Para os entrevistados, com o desenvolvimento do programa de educação permanente, a qualidade é evidenciada no processo do trabalho, onde se observa a facilidade na prática do exercício profissional mediante a execução de procedimentos. A qualidade do serviço prestado mediante os procedimentos técnicos é um resultado da EPS, o desenvolvimento comportamental e o gerencial também são resultantes da EPS bem delineada e com projeto pedagógico robusto. Além de criar um ambiente favorável e saudável para o exercício profissional, o seu impacto torna-se visível no atendimento ao paciente. Para os entrevistados, o paciente deve sentir-se seguro com relação ao seu atendimento e satisfeito pela forma que o profissional presta o seu trabalho.

Para nós tudo de bom, quanto mais eles souberem, melhor eles ficam e mais independentes. As dificuldades eles esclarecem com as pessoas corretas, as falhas podem ser evitadas, o que resulta na qualidade do serviço prestado. (ENF8)

Entendo que é essencial para aperfeiçoar nosso conhecimento, para não ficar na comodidade e sim buscar novos desafios, como enfermeiros isso facilita muito, eles tornam-se profissionais mais qualificados e há uma assistência de melhor qualidade, para os enfermeiros, isso só tem a acrescentar. (ENF5)

Com a educação permanente eu acredito que podemos evitar muitos erros. Muitos processos mudam constantemente e a EP traz as mudanças para nós, nos ajuda a melhorar a qualidade no atendimento com os pacientes. (TEC18)

\section{7- Eficácia do programa de Educação Permanente em Saúde}

Na pergunta aplicada aos dois grupos de entrevistados sobre qual a compreensão do profissional referente ao programa de EPS, o resultado mostrou uma relação 
com as respostas de outras perguntas já aplicadas, sendo estas: "O que você entende por Educação Permanente em Saúde?", “Do seu ponto de vista quais os benefícios que o Programa de EPS pode trazer para você?", "Do seu ponto de vista quais os benefícios que o Programa de EPS pode trazer para os técnicos de enfermagem e para você como enfermeiro?”. Basicamente, os dois grupos percebem que existe uma eficácia do programa de EPS na instituição. Mediante os resultados colhidos surgiram também as categorias que já foram relacionadas anteriormente: aprendizagem, a inovação do conhecimento, a segurança, qualidade no atendimento.

Antes de discorrer sobre esta categoria é importante saber o conceito de eficácia que, segundo $\mathrm{Bio}^{19}$, "diz respeito a resultados, a produtos decorrentes de uma atividade qualquer. Trata-se da escolha da solução certa para determinado problema ou necessidade”.

Com isso, entende-se que a eficácia é o final de um processo que apresenta o resultado esperado. Já Megginson et al. ${ }^{20}$ informa que a "eficácia é a capacidade de 'fazer as coisas certas' ou de conseguir resultados. Isto inclui a escolha dos objetivos mais adequados e os melhores meios de alcançá-los".

Foi possível entender que para os profissionais entrevistados, tanto os técnicos de enfermagem, como os enfermeiros, ambos fizeram uma relação da eficácia do programa com o conceito educação permanente e seus benefícios. Seguem algumas respostas:

É eficaz sim. Agora que estamos começando as metas isso ajuda-nos a fazer com mais segurança. (TEC5)

O beneficio é sempre estar aprendendo cada vez mais, tudo o que parece de novo é importante o funcionário aprender para poder passar pra frente, para os outros colegas. (TEC20)

Conforme Davini'12,"aproximar a educação da vida cotidiana é fruto do reconhecimento do potencial educativo da situação de trabalho. Em outros termos, que no trabalho também se aprende. A situação prevê transformar as situações diárias em aprendizagem, analisando reflexivamente os problemas da prática e valorizando o próprio processo de trabalho no seu contexto intrínseco. Esta perspectiva, centrada no processo de trabalho, não se limita a determinadas categorias profissionais, mas a toda equipe, incluindo médicos, enfermeiros, pessoal administrativo, professores, trabalhadores sociais e todas as variantes de atores que formam o grupo";

Relacionando a contribuição do referido autor com os dados coletados nas entrevistas, é possível vislumbrar que o resultado da educação permanente ocorre na prática diária do trabalho, onde admite-se a capacidade educativa do próprio processo laboral, em que os atores envolvidos nesta prática se transformam no ato de realizar reflexões de problemas. Pode contribuir para a implantação de novos processos, novas tecnologias, para desenvolver a criatividade, pois não envolve capacitação individual e sim coletiva no trabalho e para o trabalho.

\section{CONCLUSÕES}

Por meio da pesquisa percebeu-se que os participantes entendem que o significado de educação permanente é o mesmo que o da educação continuada, não tendo uma visão aprofundada sobre o tema e a distinção sobre os seus conceitos. Foi possível identificar os benefícios que o programa de EP traz para a equipe de enfermagem bem como para a instituição e para o paciente. Dentre os relatos citados destacase que a EP promove aprendizagem significativa, inovação do conhecimento, segurança, qualidade no atendimento, agilidade nos procedimentos diários e o compartilhar de experiências adquiridas.

Por outro lado, existem dificuldades por parte da equipe de enfermagem em ter acesso às ações oferecidas pela EP. Os técnicos e enfermeiros relataram que as dificuldades de acesso estão relacionadas à falta de tempo, déficit de funcionários e aos horários em que ocorrem as ações educativas. 
Ficou evidente que a falta de colaboradores no setor de trabalho sobrecarrega os profissionais do plantão. Esse tipo de situação não propicia que o profissional tenha condições de participar das ações educativas devido à alta demanda de trabalho no setor.

Sobre a percepção da eficácia da educação permanente na instituição, os dois grupos de profissionais participantes do estudo entendem que a EP é eficaz, mesmo que ainda existam algumas dificuldades, a maioria valoriza as ações educativas promovidas pela instituição.

Ao finalizar este estudo, as propostas de melhorias que se destacam são: promover aos enfermeiros ações de esclarecimento sobre o conceito de educação permanente facilitando a sua aplicação na prática diária de trabalho; promover práticas educativas no próprio setor conduzidas pelo enfermeiro, sendo este um facilitador para potencializar a proposta da Educação Permanente; rever a agenda das ações educativas que ocorrem fora do setor para contemplar os colaboradores do período noturno, ofertando horários após a troca de plantão inicial; considerar a realização de cursos com os temas sugeridos pelos participantes da pesquisa que serão repassados para a instituição.

Por fim, destaca-se a importância de envolver a equipe de enfermagem nas ações elaboradas pelo setor de EP da instituição, e principalmente incentivar os enfermeiros, que de certa forma exercem um papel de liderança, para serem multiplicadores desta prática de compartilhamento de conhecimentos, experiências, reflexões e questionamentos no exercício diário das atividades que a EPS propõe, criando assim um ambiente que promova mudanças através das problemáticas levantadas e da participação de todos os atores envolvidos.

\section{REFERÊNCIAS}

1. Gadotti M. Educação e poder: introdução à pedagogia do conflito. 8 ed. São Paulo: Cortez, 1988.

2. Paiva V, Rattner H. organizadores. Educação Permanente e capitalismo tardio. São Paulo: Cortez, p. 67-97, 1985.

3. Davini MC. Practicas laborales em los servicios de salud: Las condiciones del aprendizaje. In: Haddad J. Q, Roschke MAC, DavinI MC. Educación permanente de personal de salud. Washington: Organización Panamericana dela Salud, p. 10925, 1994- [acesso em 2016 set 18]. Disponível em: https://cursos. campusvirtualsp.org/mod/resource/view.php?id=19363.

4. Ministério da Saúde (BR). Conselho Nacional de Secretários de Saúde. As Conferências Nacionais de Saúde: Evolução e perspectivas. Conselho Nacional de Secretários de Saúde. Brasília: CONASS, 2009.

5. Ministério da Saúde (BR). Secretaria de Gestão do Trabalho e da Educação na Saúde. Departamento de Gestão da Educação em Saúde. Política Nacional de Educação Permanente em Saúde. Brasília: Ministério da Saúde, 2009.

6. Torres MDF. Estado, democracia e administração pública no Brasil. Rio de Janeiro: Editora FGV, 2004. 224 p.

7. MindManager. MindManager Enterprise License Program. Creativity \& Problem-solving. [acesso em 2016 mar 18]. Disponível em: https://www.mindjet.com/ mindmanager-2016/2016.

8. Ministério da Saúde (BR). Comissão Nacional de Ética em Pesquisa. Conselho Nacional de Saúde. Normas regulamentadoras de pesquisa envolvendo seres humanos. Resolução n. 466/2012. Brasília: Ministério da Saúde, 2012b.

9. Minayo MCS. Introdução. In: Minayo MCS, Assis SG, Souza ER (Org.). Avaliação por Triangulação de Métodos: Abordagem de Programas Sociais; Rio de Janeiro: Fiocruz, 2010. 19-51

10. Freire P. Pedagogia da Autonomia: saberes necessários à prática educativa. 4⿳亠丷a ed. São Paulo: Paz e Terra; 2009.

11. Ausubel DP. Aquisição e Retenção de Conhecimentos: Uma Perspectiva Cognitiva. Lisboa: Plátano; 2003.

12. Ministério da Saúde (BR). Política de educação e desenvolvimento para o SUS: caminhos para a educação permanente em saúde: pólos de educação permanente em saúde. Brasília: Ministério da Saúde; 2004.

13. Colomé ICS, Lima MADS, Davis R. Visão de enfermeiras sobre as articulações das ações de saúde entre profissionais de equipes de saúde da família. Rev Esc Enf. USP. 2008; 42,(2): 256-261.

14. Umann J, Guido LA, Leal KP, Freitas EO. Absenteísmo na equipe de enfermagem no contexto hospitalar. Ciên Cuid e Saúde. 2011; 10(1): 184-190.

15. World Health Organization (WHO) / Summary of the evidence on patient safety: implications for research. 2008; WHO press. 
A eficácia da educação permanente na percepção da equipe de enfermagem de um hospital filantrópico do Paraná

16. Silva LAA. Ferraz F, Lino MM, Backes VMS, Schmidt SMS. Educação permanente em saúde e no trabalho de enfermagem: perspectiva de uma práxis transformadora. Rev Gaúcha Enf. 2010; 31(3): 557-561.

17. Jorge MC, Mônaco TG, Mendes AMC. Qualidade no atendimento pelo enfermeiro no hospital-dia. Rev Inst Ciência Saúde. 2008; 26(1): 27-34.

18. Mello CHP, Silva CES, Turrioni JB, Souza LGM. ISO 9001: 2008 Sistema de Gestão da Qualidade para Operações de Produção e Serviços. São Paulo: Atlas, 2009.

19. Bio SR. Sistemas de Informação: um enfoque gerencial. São Paulo: Atlas; 1996. 20-23.

20. Megginson LC, Mosley DC, Pietri Jr PH. Administração: conceitos e aplicações. 4 ed. São Paulo: Harbra; 1998. 11-12.

21. Davini MC. Enfoques, problemas e perspectivas na educação permanente dos recursos humanos de saúde. In: Ministério da Saúde. Política Nacional de Educação Permanente em Saúde. Brasília: Ministério da Saúde; 2009. 39-63. 